\title{
O estágio na formação de professores: um relato de experiência e sua contribuição para o aprimoramento da prática docente
}

\author{
Caroline dos Santos Giuliani ${ }^{1}$ \\ Angélica Pott de Medeiros ${ }^{2}$ \\ Andreia Inês Dillenburg 3
}

\section{Resumo}

Devido às dificuldades encontradas ao exercer a profissão docente, universidades de diversos países vêm discutindo sobre os cursos de formação de professores/pedagógica. Assim, este trabalho objetivou relatar as experiências vividas, desafios e dificuldades encontradas durante um estágio curricular e analisar a influência do curso de formação de professores para o desenvolvimento da prática docente. As práticas foram propostas no curso de formação pedagógica e desenvolvidas em cursos de nível técnico da Universidade Federal de Santa Maria. Verificouse que os cursos de formação pedagógica são importantes ferramentas, assim como uma oportunidade de desenvolvimento aos bacharéis e tecnólogos, enquanto futuros professores, de desenvolver as habilidades necessárias para a prática docente.

Palavras-chave: Formação de professores; Relato; Docência.

\section{The internship in teacher education: an experience report and its contribution to the improvement of teaching} practice

\begin{abstract}
Due to difficulties found in the teaching profession, universities from different countries have been discussing teacher training courses. So, this paper aimed to report the experiences, challenges and hardships encountered during a curricular internship and analyze the influence of the teacher training course for the development of teaching practice. The practices were proposed in the course of pedagogic training and developed in technical level courses of the Federal University of Santa Maria. It was verified that pedagogical training courses are important tools, as well as an opportunity for the bachelors' and technologists' development, as future teachers, to develop the necessary skills for teaching practice.

Keywords: Teacher training; Report; Teaching.
\end{abstract}

\section{Considerações iniciais}

A necessidade da formação de professores para atuar na Educação Básica, sustentada pela Lei de Diretrizes e Bases da Educação Nacional - Lei 9.394/96 impulsiona a criação de programas de formação pedagógica. Estes cursos são direcionados especialmente aos professores, portadores de diploma de educação superior, que pretendam se dedicar à educação

\footnotetext{
${ }^{1}$ Universidade Federal de Santa Maria, Santa Maria - RS, carolgiuliani2@yahoo.com.br.

2 Universidade Federal de Santa Maria, Santa Maria - RS, apm_angelica@yahoo.com.br.

${ }^{3}$ Universidade Federal de Santa Maria, Santa Maria - RS, andreia.ines.d@gmail.com.
} 
básica (BRASIL, 1996). Fator que reforça a exigência de cursos que supram os problemas relacionados ao distanciamento do processo de formação docente e a atuação profissional, assim como, da preparação de professores harmonizados com as práticas pedagógicas no sentido de construir competências e habilidades (PEREIRA, 2004). Percebe-se que muitas instituições de ensino superior se mobilizaram no sentido da criação de licenciaturas para suprir esta necessidade.

Diante disso, em 2009, a Universidade Federal de Santa Maria (UFSM), criou o Programa Especial de Graduação de Formação de Professores para a Educação Profissional e Tecnológica (PEG), objetivando formar professores em nível superior para a docência. A partir do ingresso do discente como portador de diploma de bacharel, ou tecnólogo em curso superior, o curso proporciona uma formação pedagógica geral, a partir da formação metodológica e prática.

O Estágio Curricular Supervisionado do referido programa, com duração de 30 horas, foi realizado nos cursos Técnicos em Agropecuária e Administração, ambos do Colégio Politécnico da UFSM. As aulas foram ministradas nas disciplinas de Produção Agroindustrial, do Curso Técnico em Agropecuária, e Introdução a Custos e Gestão da Qualidade no Curso Técnico em Administração. Neste cenário, questionam-se quais as reflexões que emergem de uma prática de estágio e como esta influencia na atuação docente.

A partir disso, o presente relato de experiência busca relatar as experiências vividas, desafios e dificuldades encontradas durante o estágio docente curricular realizado em Cursos Técnicos da Universidade Federal de Santa Maria, assim como analisar a influência do curso de formação de professores como ferramenta de desenvolvimento ao docente.

\section{Metodologia}

A presente pesquisa caracteriza-se como qualitativa, a qual segundo Gil (2002) é menos formal do que a análise quantitativa. Entende-se por pesquisa a atividade básica da ciência na sua indagação e construção da realidade. A pesquisa alimenta a atividade de ensino e a atualiza diante da realidade do mundo (MINAYO; DESLANDES; GOMES, 2009). A análise qualitativa depende de diversos fatores, como a natureza dos dados coletados, extensão da amostra, instrumentos de pesquisa e pressupostos teóricos que conduziram a investigação. Pode-se, 
contudo, definir esse processo como uma sequência de atividades, que envolve a redução dos dados, sua categorização, interpretação e a redação do relatório.

Segundo Minayo et al. (2002), a pesquisa qualitativa responde a questões muito particulares e se preocupa com um nível de realidade que não pode ser quantificado. Isto é, ela trabalha com o universo de significados, motivos, crenças, aspirações, valores e atitudes, que corresponde a um espaço mais profundo dos processos e das relações que não podem ser reduzidos à operacionalização de variáveis.

A coleta de dados ocorreu por meio da análise e discussão dos relatórios e práticas desenvolvidas no Estágio Curricular Supervisionado III. As discussões ocorreram por meio de Grupos Focais (GF). Os Grupos Focais são grupos de discussão que debatem sobre um tema em particular, essa técnica se distingue por possuir características próprias, principalmente pelo processo de interação entre os grupos, que é uma resultante da busca de dados (KITZINGUER; BARBOUR, 1999).

Em uma vivência de proximidade, o Grupo Focal permite que o processo de interação grupal se desenvolva, contribuindo para as trocas, descobertas e participações (DEBUS, 1997; DALL'AGNOL; TRENCH, 1999).

De acordo com lervolino e Pelicioni (2001), o GF é adequado para ser consultado em estágios de exploração de uma pesquisa, quando se pretende ampliar a avaliação e compreensão a respeito de um programa, projeto ou serviço. Também pode ser associado a outras técnicas de coleta de dados simultaneamente.

Este estudo consiste em um relato de experiência vivenciado pelas alunas da disciplina de Estágio Curricular Supervisionado III, do Programa Especial de Graduação de Formação de Professores para a Educação Profissional (PEG) da Universidade Federal de Santa Maria realizado durante o segundo semestre de 2016.

O Estágio Curricular Supervisionado, com duração de 30 horas foi realizado nos cursos Técnicos em Agropecuária e Administração. Ambos do Colégio Politécnico da UFSM. As aulas foram ministradas nas disciplinas de Produção Agroindustrial, do Curso Técnico em Agropecuária, e Introdução a Custos e Gestão da Qualidade no Curso Técnico em Administração, no período de agosto a dezembro de 2016. 


\section{Referencial teórico: o estágio no curso de formação de professores}

O Programa Especial de Graduação de Formação de Professores para a Educação Profissional e Tecnológica (PEG), criado em 2009, tem como objetivo formar professores em nível superior para a docência. Este proporciona uma formação pedagógica geral, a partir da formação metodológica e prática.

O curso conta com uma carga horária de 315 horas de estágios, desenvolvendo atividades importantes para a formação profissional. Neste processo pedagógico, o acadêmico gera um vínculo entre a formação teórico-científica e a realidade. Esta articulação possibilita que o estudante estabeleça relações entre a teoria, à prática e as situações do cotidiano.

Conforme a Lei № 11.788 de 25 de Setembro de 2008, que dispõe sobre o estágio de estudantes, estágio é ato educativo escolar supervisionado, desenvolvido no ambiente de trabalho. Visa à preparação para o trabalho produtivo de educandos que estejam frequentando o ensino regular em instituições de educação superior, de educação profissional, de ensino médio, da educação especial e dos anos finais do ensino fundamental, na modalidade profissional da educação de jovens e adultos. O estágio faz parte do projeto pedagógico do curso, além de integrar o itinerário formativo do educando. Visa também ao aprendizado de competências próprias da atividade profissional e à contextualização curricular, objetivando o desenvolvimento do educando para a vida cidadã e para o trabalho.

De acordo com as normas de estágio do Programa Especial de Graduação, no Estágio Supervisionado III " $A$ " ou Docência Orientada, o estudante estagiário deverá planejar e ministrar, no mínimo, 30 horas-aula. As atividades ocorrem em espaços formais e não formais de ensino, sob a supervisão dos professores orientadores. Nessa etapa, o estágio deve ser acompanhado pelo professor orientador da UFSM e pelo professor regente da turma, ou responsável, que também avaliará o processo de docência, para a qual será disponibilizado um formulário contendo os itens a serem avaliados.

A distribuição da carga horária semestral, fundamentalmente, envolve as seguintes ações: Conceber ações e conhecimentos que definem a prática docente; planejar as atividades que circunscrevem a prática docente; receber orientações sobre os planejamentos educacionais pelos professores orientadores; refletir criticamente sobre a prática desenvolvida nos espaços 
do estágio.

A orientação do estagiário é feita pelo professor orientador, ao longo do desenvolvimento das diferentes atividades realizadas. Os professores regentes dos espaços de realização do estágio são, também, responsáveis pela supervisão das atividades desenvolvidas. O acompanhamento do desempenho do estagiário, relacionado a todas as atividades desenvolvidas, é de responsabilidade do professor orientador, subsidiados pelo professor regente.

\section{A prática do estágio: da formação ao planejamento}

Segundo Bossle (2002), planejamento de ensino é uma construção orientadora da ação docente, que como um processo, organiza e dá direção à prática coerente com os objetivos a que se propõe. Tem que responder aos seguintes questionamentos: Como? Com quê? O quê? Para quê? Para quem? na forma de um plano. Para que se concretize a atividade docente é necessário que haja outras instâncias de planejamento que são o projeto político-pedagógico e o projeto curricular, que nortearão a ação docente coesa e responsável, e precedem o planejamento de ensino propriamente dito.

As práticas pedagógicas incluem desde o planejar e estruturar a dinâmica dos processos de aprendizagem até caminhar no meio de processos que vão além dela, garantindo o ensino de conteúdos e de atividades considerados fundamentais para aquele estágio de formação do aluno, e, através desse processo, criar nos alunos mecanismos de mobilização de seus saberes anteriores construídos em outros espaços educativos (FRANCO, 2015).

Durante o estágio foi elaborado um planejamento de cada aula, um plano de ensino e um relato com pontos positivos e pontos negativos, assim como apontamentos do que poderia ser melhorado para as próximas aulas. O processo foi acompanhado pelo professor orientador do estágio ligado ao PEG.

De acordo com Franco (2015), planeja-se o ensino com a intenção da aprendizagem futura do aluno, porém, por mais eficiente que o planejamento de ensino seja não será possível controlar a imensidão de possibilidades das aprendizagens que cercam o aluno. Como saber o que o aluno aprendeu? Como planejar o próximo passo de sua aprendizagem? Precisamos de

$$
\text { Periódico Horizontes - USF - Itatiba, SP - Brasil - e019047 }
$$


planejamento de ensino ou de acompanhamento crítico e dialógico dos processos formativos dos alunos?

\section{Resultados e discussões}

Os principais pontos observados durante o estágio podem ser divididos em três grandes categorias: ações e pesquisas que antecedem o estágio, execução do estágio e reflexão e escrita sobre a prática docente.

- Ações e pesquisas que antecedem o estágio: Em um primeiro momento considerou-se a realização de uma análise observacional no local de estágio para conhecer aspectos relacionados ao perfil institucional (Projeto Político Pedagógico, equipe pedagógica, perfil do egresso, dentre outros aspectos). Em um segundo momento, partiu-se para a identificação do grupo discente (perfil do ingressante, faixa etária da turma, e se existe alunos com deficiência ou com dificuldades de aprendizagem). Em um terceiro momento, buscou-se mapear previamente os recursos disponíveis para a operacionalização das ações do estágio (estrutura disponível, laboratórios, projetos).

- Execução do estágio: considerou-se essencial a orientação e acompanhamento do docente orientador do curso de formação de professores e o feedback do professor onde foi realizada a prática após cada aula ministrada, a fim de revisar o planejamento das aulas, para que houvesse ou não modificações.

Um aspecto central na realização do estágio é que o estagiário busque ao longo da prática conectar seu conhecimento científico com o campo de atuação, trazendo exemplos práticos da realidade e do cotidiano, com vocabulários acessíveis aos discentes. Diante disso, também se observou que foi relevante e motivador proporcionar aos discentes visitas técnicas que reafirmam a importância dos conhecimentos teóricos para a atuação profissional.

- Reflexão e escrita sobre a prática docente: Ao final do estágio, foi elaborado um relatório, visando à reflexão, troca de experiências e a busca por novas alternativas para enfrentar as demandas e desafios da prática docente. Além de estimular a produção científica das práticas e reflexões de estágio para que possam ser disseminadas no campo acadêmico e profissional. 
Salienta-se que os estudos relacionados à formação de professores evidenciam que os saberes necessários não se detêm apenas aos conhecimentos dos conteúdos das disciplinas. Quem ensina sabe que para ensinar é preciso muito mais do que ter conhecimento sobre o conteúdo, apesar de que esse conhecimento seja fundamental. E, é recorrente a confusão de que as habilidades necessárias às práticas docentes são resumidas apenas ao talento natural dos professores. Percepções como domínio de bom senso, intuição, experiência e cultura, equívoco que prejudica o processo de profissionalização do ensino (GAUTHIER et al., 1998).

O professor em processo de formação, dentro da perspectiva de uma epistemologia, crítica da prática, enriquece-se quando percebe como construir, rever, criticar e ressignificar, em processo, tais conhecimentos (FRANCO, 2015). O saber docente não provém de uma única fonte, pois é um saber social, plural e temporal, emanado da formação profissional e das experiências cotidianas do professor. Sendo assim, os saberes docentes são caracterizados em: saber curricular, saber de formação profissional, saber experiencial e saber disciplinar (TARDIFF, 2014).

De acordo com Carvalho e Gil-Pérez (2011) são oito os elementos fundamentais ao exercício da docência: conhecimento do conteúdo que será ensinado, saber preparar as atividades, saber dirigir as atividades, saber pesquisar e utilizar os resultados de pesquisas, saber avaliar, conhecer e questionar o pensamento docente, adquirir conhecimentos teóricos sobre a aprendizagem, saber analisar de forma crítica o ensino. Esses elementos devem ser concebidos a partir de cursos de formação docente.

A formação dos futuros professores tem sofrido críticas relacionadas à sua efetividade, pois, apesar da necessidade de um profundo conhecimento acerca do conteúdo que será lecionado, é necessária a integração do saber científico, a concepção de ensino/aprendizagem, assim como a prática pedagógica, para uma formação docente mais adequada (CARVALHO; GILPÉREZ, 2011).

Compreende-se que o professor tem um papel fundamental na formação social e acadêmica de seu aluno. Há mudanças constantes nas formas de aprender e ensinar, por isso os cursos de formação de professores preparam seus futuros docentes para a nova realidade da sala de aula, e estes deverão atuar como mediadores e facilitadores da aprendizagem.

Há relatos de que o professor sabe o conteúdo a ser ministrado, porém não sabe como transmitir esse conhecimento ao aluno. Assim como relatos de que o docente não sabe como 
conduzir a aula, ou que é distante e não se importa com o aluno (PACHANE; PEREIRA, 2004). Segundo Dayrell (1996), o docente deve deixar explícito o que irá abordar e despertar o interesse dos alunos para que estes participem, questionem, valorizem o professor e o que ele está ensinando.

Para construir conhecimento, o professor deve interagir com o aluno, sem que existam dois mundos diferentes: o do professor e o do aluno. Dayrell (1996) afirma que o aluno só aprende quando o conhecimento se torna significativo para ele, quando estabelece relações substantivas e não arbitrárias entre o que se aprende e o que ele conhece. Para que ocorra o processo de aprendizagem é preciso que haja um diálogo entre o conhecimento a ser ensinado e a cultura de origem de cada discente (DAYRELL, 1996). Existem diversos obstáculos na prática docente, entre os principais podemos elencar a inexperiência, a autonomia exagerada por parte do professor, as relações entre aluno e professor. A partir da vivência no processo ensinoaprendizagem durante a realização dos estágios, muitas dificuldades foram encontradas.

Primeiramente é necessário que o docente apresente conhecimento acerca do conteúdo que será ensinado (GAUTHIER et al., 1998; CARVALHO; GIL-PÉREZ, 2011; TARDIFF, 2014;). Outra postura importante é a de entrar em contato com a instituição para que os docentes estagiários tomem o conhecimento da ementa das disciplinas, com seus objetivos e os conteúdos a serem abordados. Muitas vezes estes conteúdos são novos para o estagiário ou este deverá estudá-los para construir possibilidades metodológicas que sejam positivas aos discentes. A partir daí o professor se posiciona como um pesquisador, em busca de conteúdos que serão transmitidos aos seus alunos, confirmando o argumento de Freire (2002) de que não há docente sem discente.

O conhecimento sobre o conteúdo a ser ensinado não é a única habilidade necessária ao docente, de acordo com a literatura, conhecimentos teóricos sobre aprendizagem, saber preparar atividades e dirigi-las, assim como saber avaliar, também são necessários para a prática docente. E foi com o objetivo de suprir tais necessidades que surgiu o interesse para ingressar no curso de formação de professores, onde, ao longo de três semestres foi possível aprender sobre as teorias da aprendizagem e metodologias de ensino.

Outra habilidade necessária à prática docente é o saber experiencial e essa habilidade foi uma das principais dificuldades encontradas, devido à falta de experiência. Tendo em vista que

$$
\text { Periódico Horizontes - USF - Itatiba, SP - Brasil - e019047 }
$$


o ingresso no estágio como professor estagiário contemplava apenas o conhecimento teórico acerca das disciplinas e da docência. Sabe-se que o professor deve levar em consideração o aluno, sua origem, cultura e deve buscar interação para que possa transmitir conhecimento e torná-lo significativo para o discente.

E foi assim que o estágio foi realizado, buscando pôr em prática todo o conhecimento acerca do processo de ensino/aprendizagem, desenvolvido nas disciplinas do curso de formação de professores, o que foi de suma importância, pois auxiliou no andamento das aulas. Contando com o aporte de um professor orientador do estágio, vinculado ao curso de formação de professores, contribuindo para o desenvolvimento metodológico no estágio. Tal experiência contribuiu para o saber experiencial, ou seja, a experiência docente, a qual é formada no decorrer da prática docente, o que possibilitou a conclusão do curso com esta vivência.

\section{Considerações finais}

A realização dos estágios curriculares do Programa Especial de Graduação de Formação de Professores para a Educação Profissional e Tecnológica trouxe a oportunidade de refletir sobre a prática docente e seus principais desafios. Portanto, apesar de haver a crença popular da existência do talento natural do professor, foi possível reconhecer que os cursos de formação pedagógica são importantes ferramentas para o aprimoramento da prática docente. Estes cursos proporcionam uma oportunidade de desenvolvimento aos bacharéis e tecnólogos, enquanto futuros professores, de desenvolver as habilidades necessárias para a prática docente, as quais, de maneira resumida, consistem em: conhecimento do conteúdo, conhecimento acerca de metodologia e ensino/aprendizagem, e experiência docente.

O curso de formação de professores oportuniza o desenvolvimento de duas importantes habilidades, o conhecimento pedagógico e a experiência docente. Além disso, oportuniza a vivência na prática da condução da relação aluno/professor, centrando as aulas no aluno, levando em consideração seus problemas, dificuldades e sua origem/cultura, além de relacionar a teoria com os acontecimentos cotidianos, facilitando assim, o seu aprendizado. 


\section{Referências}

BOSSLE, F. Planejamento de ensino na Educação Física - uma contribuição ao coletivo docente. Revista Movimento, Porto Alegre, v.8, n.1, p.31- 39, jan./abr. 2002. Disponível em:

<http://www.seer.ufrgs.br/Movimento/article/download/2635/1261> Acesso em: 10 jul. 2018.

BRASIL. Lei no 9.394, de 20 de dezembro de 1996. Lei de Diretrizes e Bases da Educação Nacional. Diário Oficial da União: Brasília, 23 de dez. 1996.

BRASIL. Lei no 11.788, de 25 de setembro de 2008. Dispõe sobre o estágio de estudantes e dá outras providências. Diário Oficial da União, Brasília, 26 de set. 2008.

CARVALHO, A. M. P. D.; GIL-PÉREZ, D. Formação de professores de ciências: tendências e inovações. São Paulo: Cortez, 10. ed., 2011.

DALL'AGNOL, C. M.; TRENCH, M. H. Grupos focais como estratégia metodológica em pesquisas na Enfermagem. Revista Gaúcha de Enfermagem, v.20, n.1, p.5-25, 1999.

DAYRELL, J. A escola como espaço sócio cultural: múltiplos olhares sobre educação e cultura. Belo Horizonte: Ed. UFMG, 1996.

DEBUS, M. Manual para excelencia en la investigación mediante grupos focales. Washington (USA): Academy for Educational Development, 1997.

FRANCO, M. A. S. Práticas pedagógicas de ensinar-aprender: por entre resistências e resignações. Educação e Pesquisa, São Paulo, v.41, n.3, p.601-614, jul./set. 2015.

FREIRE, P. Pedagogia da autonomia. 25. ed. Rio de Janeiro: Paz e Terra, 2002.

GAUTHIER C. et al. Por uma teoria da pedagogia: pesquisas contemporâneas sobre o saber docente. ljuí: Ed. Unijuí, 1998.

GIL, A. C. Como elaborar projetos de pesquisa. 4. ed. São Paulo: Atlas, 2002.

IERVOLINO, S. A.; PELICIONI, M. C. F. A utilização do grupo focal como metodologia qualitativa na promoção da saúde. Revista da Escola de Enfermagem da USP, v.35, n.2, p. 115-121, 2001.

KITZINGER, J.; BARBOUR, R. S. Introduction: the challenge and promise of focus groups. In: KITZINGER, J.; BARBOUR, R. S. (Orgs.). Developing focus group research: politics, theory and practice. London (UK): Sage, 1999, p.1-20.

MINAYO, M. C. S. et al. Pesquisa social: teoria, método e criatividade. 21. ed. Rio de Janeiro: Vozes, 2002. 
MINAYO, M. C. S.; DESLANDES, S. F.; GOMES, R. Pesquisa social: teoria, método e criatividade. 28. ed. Rio de Janeiro: Vozes, 2009.

PACHANE, G. G.; PEREIRA, E. M. A. A importância da formação didático pedagógica e a construção de um novo perfil para docentes universitários. Revista Iberoamericana de Educación, v.35, n.1, p.1-13, 2004.

PEREIRA, L. A. C. A formação de professores para a educação profissional. Fórum de Educação Profissional. Brasília, 2004.

TARDIFF, M. Saberes docentes e formação profissional. Rio de Janeiro: Vozes, 2014.

Recebido em julho de 2018.

Aprovado em junho de 2019. 